\title{
Implementation of high-voltage kicker system for "ROSTU" middle-size league robot soccer
}

\author{
Dzikri Hasbialloh, Simon Siregar, Muhammad Ikhsan Sani \\ Department of Computer Engineering, Faculty of Applied Science, Telkom University, Indonesia
}

\begin{tabular}{|c|c|}
\hline Article Info & ABSTRACT \\
\hline Article history: & \multirow{11}{*}{$\begin{array}{l}\text { Middle-size robot soccer is one of the divisions that competed in national } \\
\text { events such as the National Indonesia Robotics Competition and international } \\
\text { competitions such as the middle size league (MSL). One of the main } \\
\text { components in soccer robots is the kicker system. The kicker system is } \\
\text { expected to be high torque, robust, and safe. In this work, a high voltage } \\
\text { kicker system is designed and evaluated to substitute ROSTU's previous } \\
\text { kicker system. This high voltage solenoid-based kicker system works at } 380 \mathrm{~V} \\
\text { and uses the electromagnetic force principle to move a ball. The performance } \\
\text { criteria of the kicker system are it can move a ball with a mass of around } 1 \mathrm{~kg} \\
\text { for a minimum range of } 3 \mathrm{~m} \text { and control the charging and discharging process } \\
\text { in high voltage conditions. The experiment results show that the kicker system } \\
\text { can move a ball with a mass of } 1.06 \mathrm{~kg} \text {, a difference kick distance from } \\
100 \mathrm{~cm} \text { to } 350 \mathrm{~cm} \text {, and a monitoring system that can show information about } \\
\text { the capacitor voltage and system status. }\end{array}$} \\
\hline Received Feb 24,2020 & \\
\hline Revised Jan 18,2021 & \\
\hline & \\
\hline Accepted Oct 12, 2021 & \\
\hline Keywords: & \\
\hline Kicker system & \\
\hline Middle size league & \\
\hline Robot soccer & \\
\hline Solenoids & \\
\hline Transistor IGBT & \\
\hline
\end{tabular}

This is an open access article under the CC BY-SA license.

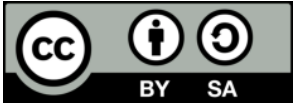

Corresponding Author:

Simon Siregar

Department of Computer Engineering, Telkom University

Jl. Telekomunikasi Jl. Terusan Buah Batu, Sukapura, Kec. Dayeuhkolot, Kota Bandung

Jawa Barat 40257, Indonesia

Email: simon.siregar@tass.telkomuniversity.ac.id

\section{INTRODUCTION}

This paper is the development of our previous research. Early research on wheeled soccer robots began in 2016 [1], 2017 which based on [2], and 2018 [1]. The first version of the ball kicker system for a small soccer robot system [3] was based on solenoid 24V in [4], [5]. Figure 1 shows our previous ROSTU robot soccer system. ROSTU stands for Robotic Soccer of Telkom University which represent one of Telkom University robotic team in The National Indonesian Robot Competition (known as KRI). Type of the ball used in the match was ping pong balls [6]. This system works as follows: Arduino Mega 2560 will receive position data from Raspberry Pi [7] in real-time [6], [8]-[10]. This position data is processed in raspberry pi from digital image processing. The raspberry pi processor was chosen due to its open-source characteristic [11]. Digital image processing is a process to identify the position of the ball in a mapped camera frame [9], [12], [13]. After the position of the ball is received, Arduino Mega 2560 will turn on the dc motor to chase the ball according to the data. Furthermore, Arduino Mega 2560 will read the compass sensor and direct the ball to the goal position and turn on the solenoid to kick the ball [14].

In the 2017 version, the soccer robot design is based on the National Indonesian Robot Competition 2017 rules [15], [16], which uses FIFA's standard futsal ball. The ball's weight is 500gr. Because of the weight, the kicker system is changed to the electro-pneumatic system, which has a greater thrust force. However, the kicker based on electro-pneumatic has several disadvantages, such as the dimension of the electro-pneumatic system is more significant than the previous one; the process of air reloading time takes 
some time. Moreover, the power and direction of the kick and the number of available kicks are very dependent on existing pressure. Based on this background, a kicker system-based high-voltage solenoid system is chosen. The high voltage solenoid $( \pm 380 \mathrm{~V})$ kicker system has an advantage in the number of kick styles it can produce. The design of this kicker system has to consider the number of solenoids turns (n), the supply voltage, and the electrical current to produce the optimal force $(\mathrm{F})$. Moreover, the safety of a high voltage system has to be designed to protect the low voltage system inside the ROSTU soccer robot [17]. Based on this background, the primary purpose of this paper is to design a high voltage kicker system with a solenoid.

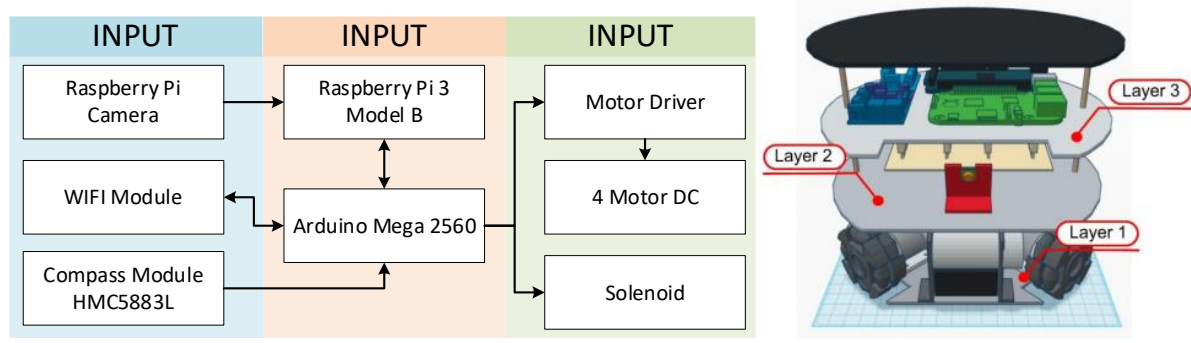

Figure 1. Previous robot soccer system [14]

\section{ELECTRICAL DESIGN}

The solenoid-based kicker is one of the research challenges in the MSL Competition [18]. In a high voltage solenoid-based kicker system, there are ten main components based on [19]. The block diagram of the ROSTU's Kicker System is shown in Figure 2. The description of how the system works is as:

a. The power supply is using a $4 \mathrm{~S}$ battery with $5200 \mathrm{mah}$. This component provides a kicker system voltage suppression to perform kicks.

b. Display system. This section consists of a 16x2 LCD, three pushbuttons, and two LEDs. The function of this section is to monitor the kicker system condition.

c. Relay. This component serves as a switch from battery to Current limiter. So it allows for on/off the stepup transformer as needed and to avoid the step-up transformer overheating due to continuous work.

d. Step-up Transformer. This component works to increase the voltage from 16v to 400v battery. This component is vulnerable to damage. Damage occurred due to the backflow of capacitors, Overheat due to continuous work, and overcharge. To overcome this, the safety diodes were installed between step up and capacitor with a cooling fan to control the temperature of the step-up transformer.

e. Switch 1. This component uses the G80N60 transistor. This component works for:

f. Connect the power flow from step up to the capacitor in the charging process.

g. To decide the power flow from step up to capacitor when in charging process is fully charged (390v), the maximum voltage of the capacitor must not exceed 390v.

h. Capacitor. This component serves as an electrical charge bank which needed to supply electrical current for the kicking process. This capacitor specification is $6200 \mathrm{uF} 400 \mathrm{v}$. It takes 20 seconds to fill the capacitor. Under full charge conditions, the one-time shot kick will reduce the voltage to $50 \%$.

i. Switch 2. This component uses the G80N60 transistor. This transistor works to connect and disconnect electricity from the capacitor to the solenoid during the kicking process.

j. Solenoid. This component serves to convert electric energy into motion energy. The solenoid is made of a $0.4 \mathrm{~mm}$ diameter copper wire wielding. The $0.4 \mathrm{~mm}$ diameter is chosen to facilitate the process of solenoid winding. To increase the value of the inductance of the solenoid is done by multiplying the number of wires wrapped simultaneously.

k. Voltage sensor. This component works to measure the voltage in the capacitor. The voltage value will be sent to Arduino to be a parameter in the system.

1. Arduino. This component works to control the kicker system. Algorithms used are:

- Arduino reads voltage sensor values.

- If the voltage is less than 360, the Arduino will turn on the relay and switch one for the charging process.

- If the voltage is more than or equal to 380, the Arduino will turn off switch one and the relay.

- If the voltage is more than 200 and the Arduino receives the command from the image processing system to do the kick, then the Arduino will turn on switch two. 
- If the voltage is less than 200 and the Arduino receives the command from the image processing system to perform kick, then Arduino will not turn on switch two until the voltage value is more than or equal to 200 .

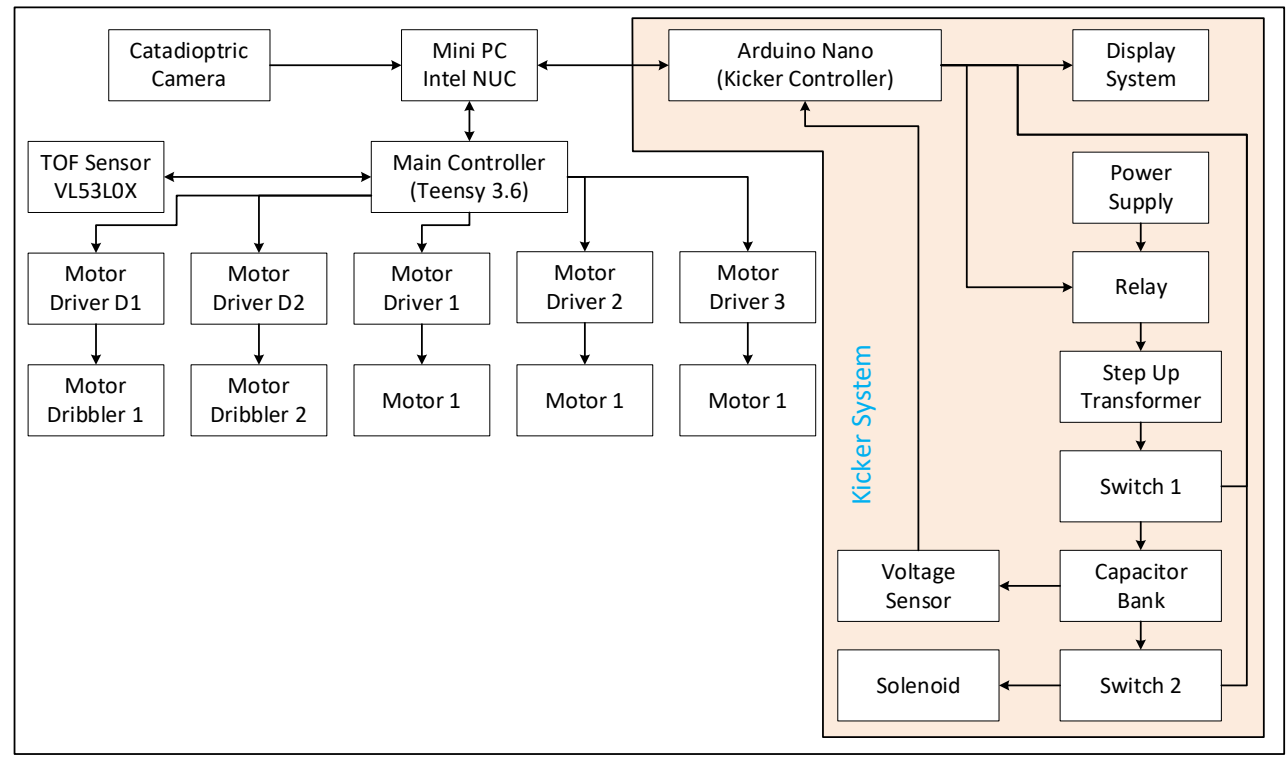

Figure 2. Design of ROSTU kicker controller module system

Figure 3 shows ROSTU internal component for the kicker mechanism. ROSTU uses three DC $24 \mathrm{~V}$ motors with an Omni wheel to control the motion. Moreover, the dribler system uses two 24V DC motors with a worm gearbox. The catadioptric camera lens at the top of the robot is used to maximize the camera view angle for computer vision. All components of the controller and mini PC are positioned at the top (far from the solenoid and DC motor) to avoid the damage caused by the electromagnetic pulse from the solenoid during the kicking process. All electronic components are protected by a casing made of $3 \mathrm{~d}$ print (plastic) [20].

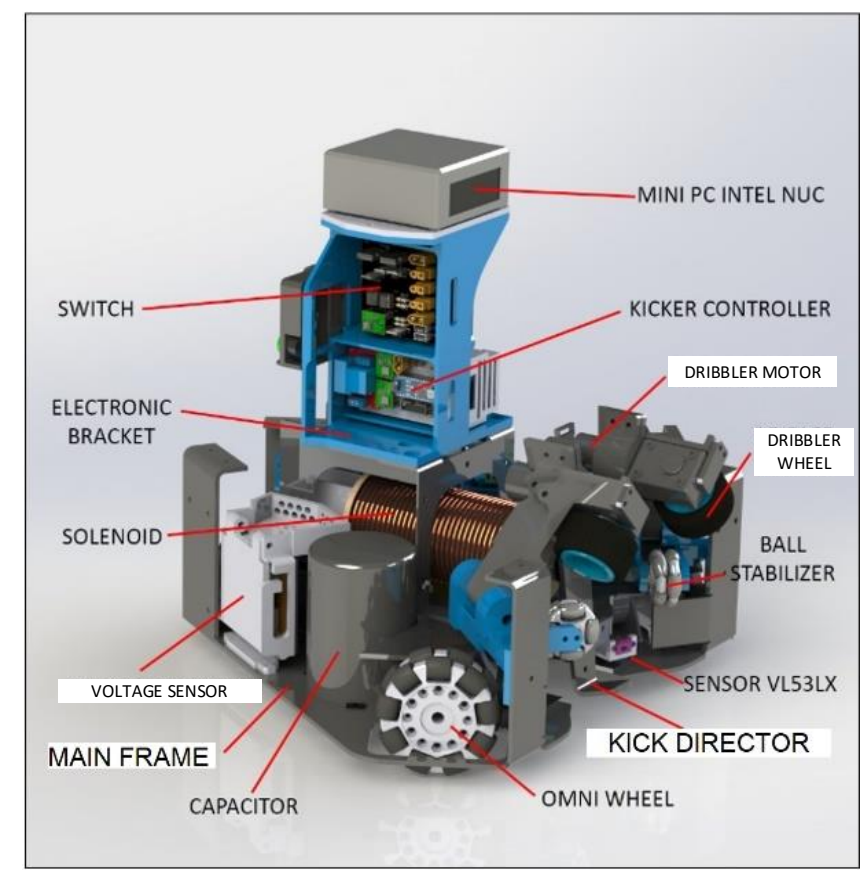

Figure 3. Rendered mechanical design of ROSTU robot soccer system 


\section{MECHANICAL DESIGN}

Figure 4 shows the kicker solenoid-based design. The design enables the kicker system to do push the ball in front of the robot and avoids ball friction with the floor when the robot moves [21], [22]. The kicker system works as follows: the copper coil is energized with an electrical current to produce induction force, induction force will push the ferromagnetic-based plunger, and the plunger will push the ball. This kicking system was designed to push the ball with an elevation angle of $40.46^{\circ}$. Figure 5 describes the detailed design of the solenoid system. The solenoid system consists of an isolating frame, a copper wire coil, and a ferromagnetic-based plunger. The number of wire windings on a copper wire coil depends on the designed force.

One value that affects the force produced by a solenoid system is the resistance value of the coil. This resistance value will affect the value of the electric current. Increasing or decreasing the number of wires in the parallelized winding wired will vary the solenoid resistance value. Table 1 shows the wielding scheme for the solenoid system for the ROSTU robot.

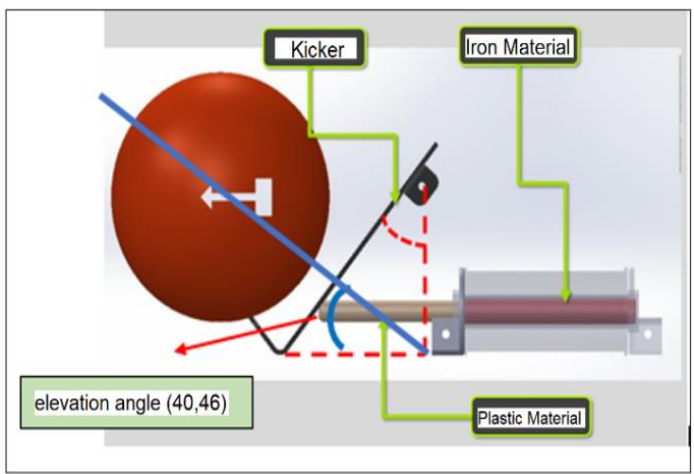

Figure 4. Kicker design of ROSTU robot soccer system

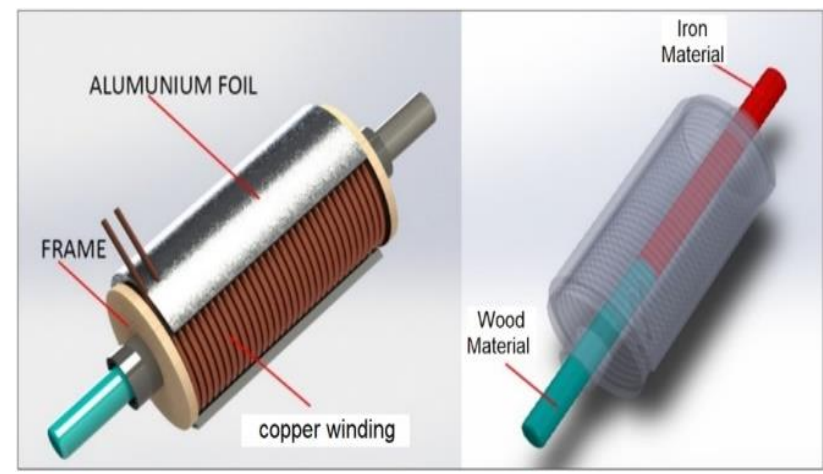

Figure 5. Solenoid design of ROSTU robot soccer system

Table 1. Wielding scheme for selenoid system

\begin{tabular}{c}
\hline Number of paraleled winding \\
\hline 1 \\
(Single wire winding) \\
2 \\
(Wire windings simultaneously \\
then both ends of the wire are \\
united) \\
3 astration of winding \\
(Wire windings simultaneously \\
then both ends of the wire are \\
united)
\end{tabular}

\section{ROSTU KICKER SYSTEM METHOD}

Based on the electrical design in section 2, Figure 6 shows the flowchart of the solenoid-based kicker system. Arduino nano communicates with the mini PC in serial communication [23]. Arduino nano will send capacitor voltage information to a mini PC. The ROSTU Robot will give orders to Arduino nano to trigger a kick motion. The ROSTU robot is run under the robot operating system (ROS) framework [24]-[26]. To communicate between Arduino nano and mini PC, the system must use the Serial ROS library. A program, which runs under Arduino nano, must act as a node (subprogram) that publishes or transmits data. The node in the main program reads the capacitor voltage information as parameters in the robot's main program algorithm. Arduino nano receives a kick command from the main program by doing a subscribe protocol (receive data) in the form of a PWM value. The Arduino obtain the PWM value and uses it as a parameter to determine the power of the kicker system. 


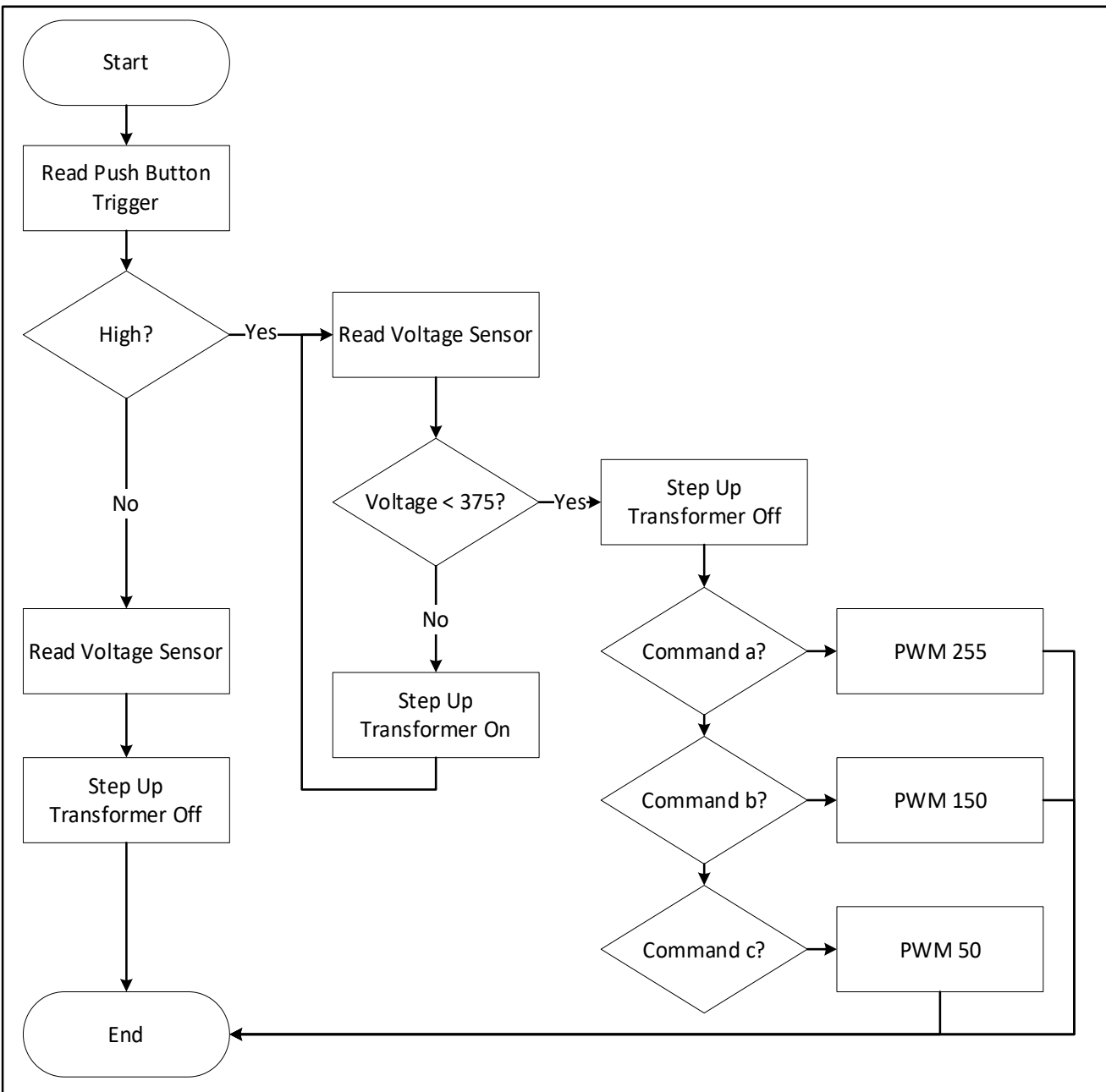

Figure 6. Proposed kicker controller flowchart

\section{RESULTS AND DISCUSSION}

\subsection{Kicker controller module experiment results}

The kicker controller, as shown in Figure 7, has several testing scenarios as follows. There are two buttons to run the experiment. Table 2 shows the experiment using the two-button in the kicker controller module. The experiment result in Table 2 shows that the kicker controller module works as in the proposed design.

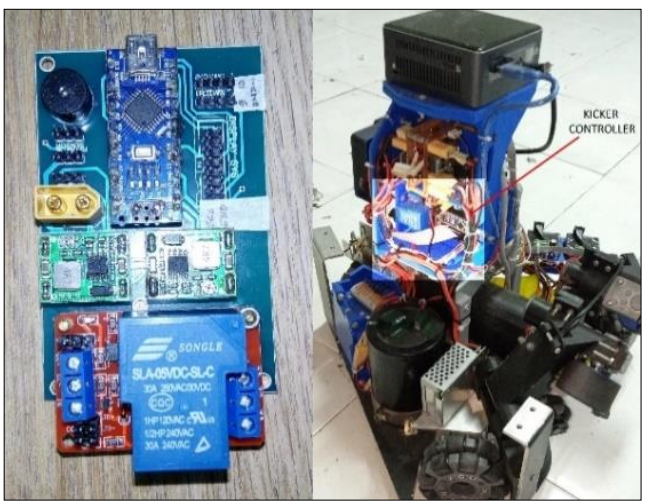

Figure 7. Kicker controller module
Table 2. Experiment result of kicker controller module

\begin{tabular}{|c|c|c|}
\hline Scenario & $\begin{array}{c}\text { Experiment } \\
\text { Result }\end{array}$ & Respond \\
\hline $\begin{array}{l}\text { The push } \\
\text { button is } \\
\text { pressed for } \\
\text { the first time }\end{array}$ & $\begin{array}{l}\text { Relay is On, Step } \\
\text { up is On, and Red } \\
\text { LED is On }\end{array}$ & $\begin{array}{c}\text { As } \\
\text { designed }\end{array}$ \\
\hline $\begin{array}{l}\text { The push } \\
\text { button is } \\
\text { pressed for } \\
\text { the second } \\
\text { time }\end{array}$ & $\begin{array}{l}\text { Relay is Off, Step } \\
\text { up is Off, and } \\
\text { Red LED is OFF }\end{array}$ & $\begin{array}{c}\text { As } \\
\text { designed }\end{array}$ \\
\hline $\begin{array}{l}\text { The system } \\
\text { charges the } \\
\text { capacitor up } \\
\text { to } 380 \mathrm{~V}\end{array}$ & $\begin{array}{l}\text { Charging process } \\
\text { stop and Buzzer } \\
\text { is sounded for } 1 \\
\text { second }\end{array}$ & $\begin{array}{c}\text { As } \\
\text { designed }\end{array}$ \\
\hline
\end{tabular}




\subsection{Monitoring display module experiment results}

The experiments on display systems, as shown in

Figure 8, show the display system can receive manual commands via a push button. Moreover, the display system can represent the kicker system status (charging or discharging) and the capacitor voltage values. Built-in LEDs can provide a simple status indicator of the kicker system. Table 3 describes The experiment scenario and experiment result for the kicker monitoring display system.

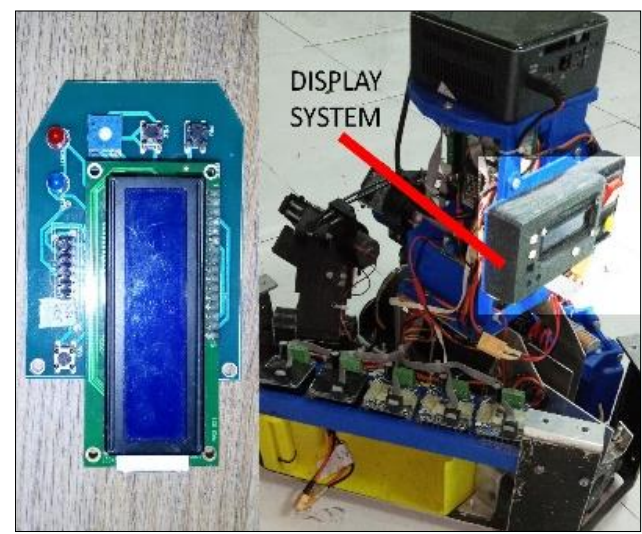

Figure 8. Kicker controller display module

Table 3. Experiment result of kicker controller display module

\begin{tabular}{ll}
\hline \multicolumn{1}{c}{ Push button Scenario } & \multicolumn{1}{c}{ Experiment Result } \\
\hline $\begin{array}{l}\text { The push button is pressed for the first } \\
\text { time }\end{array}$ & $\begin{array}{l}\text { Charging Process is executed, Red LED } \\
\text { is On, Blue LED is off. The value of } \\
\text { capacitor voltage is detected }\end{array}$ \\
$\begin{array}{l}\text { The push button is pressed for the } \\
\text { second time }\end{array}$ & $\begin{array}{l}\text { Discharging Process is executed, Red } \\
\text { LED is off, Blue LED is on. The value } \\
\text { of capacitor voltage is detected }\end{array}$
\end{tabular}

of capacitor voltage is detected

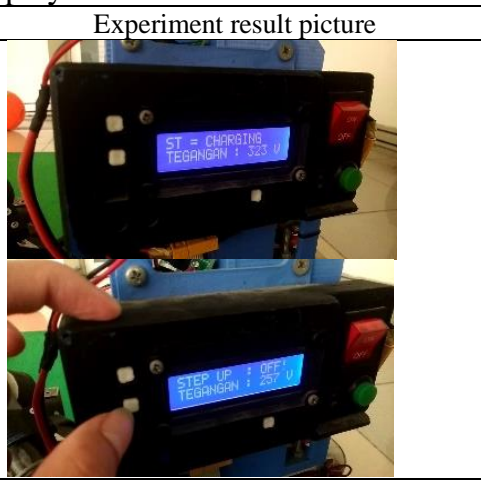

\subsection{Copper coil experiment results}

The effect of the difference winding number of copper wire experiment results shown in Table 4. From the experiment, the result shows that the higher number of copper wire winding will increase the electrical current, and will increase the inductance, which yields greater induction force.

Table 4. Experiment result of kicker director module

\begin{tabular}{ccccc}
\hline Wire size & Number of winding & Coil paralleled & Resistance & $\begin{array}{c}\text { Kick distance } \\
\text { (bounce kick) }\end{array}$ \\
\hline $0,4 \mathrm{~mm}$ & 6000 & 1 & $120 \Omega$ & $1 \mathrm{~m}$ \\
$0,4 \mathrm{~mm}$ & 6000 & 2 & $70 \Omega$ & $1,8 \mathrm{~m}$ \\
$0,4 \mathrm{~mm}$ & 6000 & 4 & $20 \Omega$ & $3 \mathrm{~m}$ \\
$0,4 \mathrm{~mm}$ & 6000 & 6 & $6 \Omega$ & $4 \mathrm{~m}$ \\
\hline
\end{tabular}

\subsection{Solenoid switch experiment results}

Table 5 shows experimental results with different PWM values. From the results can be concluded that the kick distance can be controlled by variation PWM Trigger value. The greater the PWM value will use greater the electrical current in the same voltage and will yield greater force. The maximum kick distance is $400 \mathrm{~cm}$ and the minimum distance with possible $\mathrm{PWM}$ value is $130 \mathrm{~cm}$. 
Table 5. Experiment result of kicker switch module

\begin{tabular}{ccc}
\hline PWM value & Voltage & Kick Distance (bounce kick) \\
\hline 255 & $390 \mathrm{~V}$ & $400 \mathrm{~cm}$ \\
230 & $390 \mathrm{~V}$ & $350 \mathrm{~cm}$ \\
210 & $390 \mathrm{~V}$ & $230 \mathrm{~cm}$ \\
190 & $390 \mathrm{~V}$ & $150 \mathrm{~cm}$ \\
160 & $390 \mathrm{~V}$ & $50 \mathrm{~cm}$ \\
130 & $390 \mathrm{~V}$ & $30 \mathrm{~cm}$ \\
100 & $390 \mathrm{~V}$ & $0 \mathrm{~cm}$ \\
\hline
\end{tabular}

\section{CONCLUSION}

This paper shows that the high voltage solenoid-based kicker system can kick up the kick with a maximum distance of 4 meters. The maximum spacing produced is shorter than 0.5 meters than the design. The PWM value can control the kick distance. Furthermore, the display system can monitor kicker system conditions with the capacitor voltage value and the system status. In designing a football robot kicker system, it is necessary to consider other factor factors such as friction force, solenoid heat, or transistor current quality. Some improvement that could be done on the future research is by changing step-up transformer with larger output electrical current.

\section{ACKNOWLEDGEMENTS}

This research was supported and funded by Riset Desentralisasi-Penelitian Terapan Unggulan Perguruan Tinggi (PTUPT) from Ministry of Research, Technology, and Higher Education, Indonesia. This work was also supported by Embedded and Network System Research Laboratory and Robotic SAS team, Faculty of Applied Science, Telkom University.

\section{REFERENCES}

[1] S. Siregar, I. bin Ibrahim, M. I. Sani and M. I. Sari, "Design of Computer Vision Based Ball Detection System on Wheeled Robot Soccer," 2018 International Conference on Control, Electronics, Renewable Energy and Communications (ICCEREC), 2018, pp. 46-49, doi: 10.1109/ICCEREC.2018.8711988.

[2] C. L. Martinez et al., "Tech United Eindhoven, winner RoboCup 2014 MSL: Middle Size League," in Conference Robot Soccer World Cup, vol. 8992, pp. 60-69, 2015, doi: 10.1007/978-3-319-18615-3_5.

[3] M. Hill, N. Jones and M. Shanahan, "Small-Size Soccer Robots," 2005 Level IV Design Project Final Report, The University of Adelaide Australia, 2005.

[4] C. C. Wong, C. T. Cheng and H. M. Chan, "Design and implementation of an autonomous robot soccer system," International Journal of Advanced Robotic Systems, vol. 10, pp. 1-13, 2013, doi: 10.5772/56189.

[5] S. H. Mohades Kasaei, S. M. Mohades Kasaei and S. A. Mohades Kasaei, "Design and implementation solenoid based kicking mechanism for soccer robot applied in robocup-MSL," International Journal of Advanced Robotic Systems, vol. 7, no. 4, pp. 69-76, 2010, doi: 10.5772/10490.

[6] H. Myint, P. Wong, L. Dooley and A. Hopgood, "Tracking a table tennis ball for umpiring purposes," 2015 14th IAPR International Conference on Machine Vision Applications (MVA), 2015, pp. 170-173, doi: 10.1109/MVA.2015.7153160.

[7] G. Lencse and S. Répás, "Method for benchmarking single board computers for building a mini supercomputer for simulation of telecommunication systems," 2015 38th International Conference on Telecommunications and Signal Processing (TSP), 2015, pp. 246-251, doi: 10.1109/TSP.2015.7296261.

[8] D. Speck, P. Barros, C. Weber and S. Wermter, "Ball localization for RoboCup soccer using convolutional neural networks," in Conference: Robot World Cup, vol. 9776 LNAI, pp. 19-30, 2017, doi: 10.1007/978-3-319-687926_2.

[9] C. Lopez et al., "Tech United Eindhoven Team Description 2015," no. Figure 1, 2015.

[10] A A. Rahman and N. S. Widodo, "Colored Ball Position Tracking Method for Goalkeeper Humanoid Robot Soccer," TELKOMNIKA Telecommunication Comput. Electron. Control, vol. 11, no. 1, pp. 11-16, 2013, doi: 10.12928/telkomnika.v11i1.877.

[11] I. Mandhouj and H. Amiri, "Sonar image processing for underwater object detection based on high resolution system," Proc. Second Workshop on Signal and Document Processing (SIDOP 2012), 2012.

[12] P. A. Vallejos and J. Ruiz-del-solar, "Integrated Self-Localization and Ball Tracking in the Four-Legged Robot Soccer League," in Proceedings of the 1st IEEE Latin American Robotics Symposium, pp. 54-59, 2004.

[13] Y. Huang, J. Llach and C. Zhang, "A method of small object detection and tracking based on particle filters," 2008 19th International Conference on Pattern Recognition, 2008, pp. 1-4, doi: 10.1109/ICPR.2008.4761480.

[14] M. I. Saleh, "Design And Implementation Of Electronic And Mechanical System On Wheeled Soccer Robot," Thesis, Telkom University, 2016.

[15] D. Xiong et al., "The design of an intelligent soccer-playing robot," Ind. Rob., vol. 43, no. 1, pp. 91-102, 2016, doi: 10.1108/IR-05-2015-0092. 
[16] J. M. Calderón, E. R. Rojas, S. Rodr'iguez, H. R. Báez and J. A. López, “A Robot soccer team as a strategy to develop educational iniciatives," Latin American and Caribbean Conference for Engineering and Technology, Panama City, Panama, 2012.

[17] J. Martinovic, V. Snasel, E. Ochodkova, L. Zolta, J. Wu and A. Abraham, "Robot Soccer - Strategy Description And Game Analysis," 24th European Conference on Modelling and Simulation, Simulation Meets Global Challenges, 2012, pp. 265-270, doi: 10.7148/2010-0265-0270.

[18] R. J. G. Alaerds, "Mechanical design of the next generation Tech United Turtle," M.S. Thesis, Department of Mechanical Engineering, Technische Universiteit Eindhoven, Eindhoven, 2010.

[19] F. A. Widodo, K. Mutijarsa and W. Adiprawita, "Design and Implementation of Locomotion, Dribbler and Kicker for Soccer Robot," in International Conference on Information Technology Systems and Innovation (ICITSI), 2017, doi: 10.1109/ICITSI.2017.8267943.

[20] S S. B. Jusoh and K. Omar, "The mechanical and circuit design of robot soccer: A study," 2011 International Conference on Pattern Analysis and Intelligence Robotics, 2011, pp. 119-124, doi: 10.1109/ICPAIR.2011.5976923.

[21] Y. Liu, F. Wayne, J. Zhao and F. Wayne, "A Kicking Mechanism for a Soccer Playing Robot - a Multidisciplinary Senior Design Project,” 2009 Annual Conference \& Exposition, pp. 14.35.1-14.35.8 2009, doi: 10.18260/1-2--5612.

[22] Z. Sugianto, M. T. Kantori and M. I. Nugraha, "Dribbling and Kicking Mechanism of A Soccer Robot for " KRSBI Beroda," in 5th Indonesian Symposium on Robotic Systems and Control, 2017, pp. 61-63.

[23] J. Lunenburg, R. Soetens, F. Schoenmakers, P. Metsemakers, R. Van De Molengraft and M. Steinbuch, "Sharing open hardware through ROP, the robotic open platform," Proceedings of RoboCup 2013, Symposium Papers and Team Description Papers, 2013, 584-591.

[24] S. Bemis, "Design and development of a novel omni-directional platform," M.S. Thesis, Faculty of Engineering and Applied Science, University of Ontario Institute of Technology, Oshawa, 2009.

[25] J. Xiao, D. Xiong, W. Yao, Q. Yu, H. Lu and Z. Zheng, "Building Software System and Simulation Environment for RoboCup MSL Soccer Robots Based on ROS and Gazebo. In: Koubaa,” Robot Operating System (ROS), vol. 708, pp. 597-631, 2019, doi: 10.1007/978-3-319-54927-9_18.

[26] M. Bestmann, "Towards Using ROS in the RoboCup Humanoid Soccer League," M.S. Thesis, Department of Informatics, University of Hamburg, Hamburg, 2017.

\section{BIOGRAPHIES OF AUTHORS}
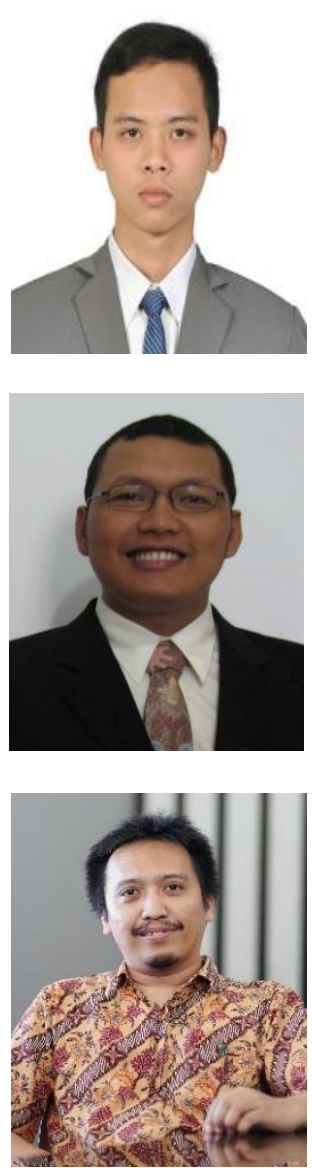

Dzikri Hasbialloh is currently work as Firmware Design Engineer in PT. Epson Indonesia. He graduated a diploma in Computer Engineering, from Faculty of Applied Science School, Telkom University.

Simon Siregar is a lecturer since 2007 at Department of Computer Engineering, Faculty of Applied Science, Telkom University. He graduated from Institut Teknologi Bandung (ITB) at 2009 and his special fields of interest are Internet of Things, Roboctic and Control System. Currently, he is a Doctorate Candidate in Institut Teknologi Bandung.e

Muhammad Ikhsan Sani is graduated from Institut Teknologi Bandung (ITB) at 2008. His special fields of interest included embedded system, robotics, and electronic circuit desing. His employment experience included the Microelectronics Center and LAPI ITB. He joined Telkom University in 2015 as a lecturer at D3 Computer Engineering program, Faculty of Applied Science. 